\title{
Stock Market Performance and the Term Structure of Credit Spreads
}

\author{
Andriy Demchuk and Rajna Gibson*
}

\begin{abstract}
We build a structural two-factor model of default where the stock market index is one of the stochastic factors. We allow the firm to adjust its leverage ratio in response to changes in the business climate for which the past performance of the stock market index acts as a proxy. We assume that the firm's log-leverage ratio follows a mean-reverting process and that the past performance of the stock index negatively affects the firm's target leverage ratio. We show that for most credit ratings our model may explain actual yield spreads better than other well-known structural credit risk models. Also, our model shows that the past performance of the stock index returns and the firm's assets beta have a significant impact on credit spreads. Hence, our model can explain why credit spreads may be different within the same credit rating groups and why spreads are lower during economic expansions and higher during recessions.
\end{abstract}

\section{Introduction}

Theoretical models of default can be classified as either structural or reduced form models. In structural models (see, for instance, Merton (1974), Longstaff and Schwartz (1995), Leland (1994), Leland and Toft (1996), and Collin-Dufresne and Goldstein (2001)), default occurs when the value of a latent variable, usually the firm value, hits the default boundary. In the Merton (1974), Longstaff and Schwartz (1995), and Collin-Dufresne and Goldstein (2001) models, the default boundary is set exogenously. For example, in the Merton model, the default boundary is equal to the promised principal payment at maturity, and default occurs if the value of the firm at maturity is below the principal bond value. In

\footnotetext{
*Demchuk, ad@fame.ch, NCCR-FINRISK and FAME, University of Zürich, and Gibson, rgibson@isb.unizh.ch, Swiss Banking Institute, University of Zürich, Plattenstrasse 14, 8032 Zürich, Switzerland. We thank Marc Chesney, Kyung-Ha Cho, Pierre Collin-Dufresne, René Stulz, ErnstLudwig von Thadden, participants at FAME and NCCR workshops, session participants at the 2002 European Investment Review Meeting, participants at the 7th Conference of the Swiss Society for Financial Market Research, and the 2nd International Conference on Credit Risk for valuable comments. We also thank Bjarne Astrup Jensen for a very useful discussion of our paper at the 2004 EFMA. Finally, we thank Viral Acharya (the referee) for valuable comments. This research was carried out within the project, Conceptual Issues in Financial Risk Management, of the National Centre of Competence in Research, Financial Valuation and Risk Management (NCCR FINRISK), which is a research program supported by the Swiss National Science Foundation.
} 
Leland (1994) and Leland and Toft (1996), the firm's default boundary is endogenously defined. Given the fact that the firm value is modeled as a continuous diffusion process, default is a fully predictable event in structural models. To the contrary, reduced form models (see, for instance, Jarrow, Lando, and Turnbull (1997), Duffie and Singleton (1999)) abstract from the firm value process. In this class of models, default is treated as an unpredictable event and is driven by a jump process. Reduced form models are primarily designed to fit the observed credit spreads, while structural models look at the fundamentals of default.

Structural models of credit risk pricing have been extended to allow for a second state variable. In most cases, this second state variable is the short-term interest rate (see, for instance, Longstaff and Schwartz (1995) and Collin-Dufresne and Goldstein (2001)). However, the empirical evidence on these two-factor bond pricing models' performance remains rather mixed (see Huang and Huang (2002)).

Our study is inspired by the empirical evidence that corporate bond prices and credit spreads significantly depend on the overall business climate. For example, Chen (1991), Fama and French (1989), Friedman and Kuttner (1992), and Guha and Hiris (2002) find that credit spreads behave counter-cyclically, i.e., credit spreads tend to increase during recessions and narrow during expansions. Collin-Dufresne, Goldstein, and Martin (2001) include the S\&P 500 return to proxy for the overall state of the economy and find a highly statistically significant and negative relation between credit spreads' changes and the index returns. Landschoot (2003) studies the determinants of the Euro term structure of credit spreads and also finds that the Dow Jones Euro Stoxx returns significantly and negatively affect credit spreads.

Based on these stylized facts, we propose a two-factor structural model of default that incorporates both the firm's specific risk and systematic, e.g., overall business climate, risk. In our model, the first factor is the stochastic value of the firm's assets and the second factor is the value of the stock market index. Our model aims to explain how the performance of the stock market index (which proxies for the business climate) and the firm's assets beta directly affect corporate bond prices and credit spreads. ${ }^{1}$

In this paper, we allow the firm to adjust its capital structure and, hence, its leverage ratio, dynamically. Our model is consistent with the fact that firms have target leverage ratios and time their equity and debt issues according to the business climate. Indeed, we model the dynamics of the firm's log-leverage ratio as a mean-reverting process, where the target (or long-term) leverage ratio is assumed to be negatively affected by the stock market performance. In Appendix A, we formally show that modeling the firm's book value of debt and its equity as weighted averages of past firm values and of the performance of the stock market leads to debt and equity issuance policies that are consistent with the mean reversion of the log-leverage ratio. Even though the proposed modeling is similar to the modeling in Collin-Dufresne and Goldstein (2001), our assumption about the mean-reverting log-leverage ratio is based on the market timing and trade-off theories of corporate debt-equity issuance policies, whereas Collin-Dufresne and

\footnotetext{
${ }^{1}$ There is also an indirect effect: from the CAPM, it follows that firms' asset returns depend on their covariance with the stock market returns.
} 
Goldstein derive the log-leverage dynamics endogenously by assuming that the default threshold follows a mean-reverting process and is further influenced by changes in the short-term interest rate.

A comparison of the performance of our model with the Merton (1974), Longstaff and Schwartz (1995), and Collin-Dufresne and Goldstein (2001) models suggests that our model yields credit spreads that are generally closer to actual credit spreads, especially when we look at the credit spreads of Aa, A, Baa, and Ba investment grade bonds. Our model shows that credit spreads tend to widen when the performance of the stock market index is weak, and vice versa. This pattern is consistent with the empirical evidence that credit spreads tend to be lower during economic expansions and higher during recessions. Our model also predicts that credit spreads are higher for firms with higher beta coefficients. This may explain why bonds with similar credit ratings but in different industries can have significantly different credit spreads. Finally, our model can also explain how the different term structure of credit spreads distinguishes distressed firms from "fallen angels."

The rest of the paper is organized as follows. In Section II, we make a brief review of theoretical and empirical studies on firms' capital structure choices that support our modeling of the dynamics of the leverage ratio. In Section III, we present the model and its assumptions. We describe the bond pricing methodology in Section IV. In Section V, we compare the credit spreads generated by our model with the average market yield spreads and with the spreads resulting from the Longstaff and Schwartz (1995), Collin-Dufresne and Goldstein (2001), and Merton (1974) models. We also discuss the main numerical results of our study, and conduct a sensitivity analysis. Section VI concludes the paper.

\section{Capital Structure Choices: Theory and Empirical Evidence}

Our theoretical model of corporate default is based on the assumption that firms continuously adjust their capital structure in response to changes in the business climate and also to changes in their assets' value. Namely, we assume that the firm's log-leverage ratio follows a mean-reverting process where the longterm mean leverage is negatively related to the performance of the stock market index (see equation (6)). In fact, the latter assumption rests on two hypotheses. The first one is that firms tend to decrease their leverage (for example, by issuing new equity) if their current leverage ratio is above the target value, and to increase their leverage (for example, by issuing new debt) if their current leverage ratio is below that target. This implies mean reversion in the dynamics of firms' leverage ratios. The second hypothesis about a negative relation between firms' instantaneous target leverage ratios and the stock index performance implies that firms adjust their target leverage ratios over time: they set their target leverage ratios at lower levels during periods of economic expansion and raise them during recessions. To see whether our assumption is consistent with the capital structure theory and empirical facts, we now examine the existing theoretical and empirical literature on firms' capital structure choices. 
The first hypothesis is in line with the so-called capital structure trade-off theory that is based on the view that firms trade off the tax benefits of debt financing and the costs of financial distress. Such a trade-off leads to an "optimal" capital structure choice. A number of empirical studies show that firms tend to make financing choices based on target leverage ratios (see, for example, Hovakimian, Opler, and Titman (2001), Marsh (1982)).

The second hypothesis is in line with timing models of corporate capital structure. These models are based on the evidence that firms tend to time their issuance of corporate securities. For example, Moore (1980), Marsh (1982), and Taggart (1977) document that firms prefer to issue equity when the value of equity is relatively high (which are typically periods of economic expansion), and to issue debt when interest rates are relatively low (which are periods of economic contraction). Similarly, Choe, Masulis, and Nanda (1993) show that firms tend to issue more equity than debt in expansionary periods of the business cycle. They explain these financing patterns by changes in adverse selection costs. That is, during periods of economic upturns, i.e., when the relative value of the firm's equity is typically high, the negative price reaction associated with an equity offering announcement is smaller.

In addition to theoretical and empirical studies on capital structure, we would also like to cite the study by Bancel and Mittoo (2002) who surveyed managers of firms in 16 European countries to examine the link between theory and practice of capital structure choices. The results of this survey (see Table 1) are also in favor of our modeling of the dynamics of the leverage ratio. Namely, nearly $60 \%$ of the respondents admitted that they consider a target debt ratio when issuing equity, and that they prefer to issue equity when the stock price has recently risen. Nearly $45 \%$ of the surveyed managers said that they would rather issue debt when interest rates are low or when their equity is undervalued. In another study, nearly two-thirds of the surveyed CFOs in the U.S. admitted to pursuing a market timing strategy (Graham and Harvey (2001)). ${ }^{2}$

TABLE 1

The Determinants of Securities' Issuance Policies

Table 1 presents the results of a survey of European firms on the determinants of capital structure choice: the three most frequent answers regarding equity and debt issuances.

\footnotetext{
${ }^{2}$ Note that in the same study Graham and Harvey find that cash management considerations essentially affect the choice of the maturity of the debt instruments issued. They claim that "for instance, many companies issue long-term debt so that they do not have to refinance in bad times" (p. 18).
} 


\section{The Model}

We derive a structural two-factor model of default where the value of the firm's assets and the stock market index are the underlying stochastic factors. In the model, we assume that the firm continuously adjusts its capital structure, i.e., issues either equity or debt, in response to the observed past returns of the stock market index and to changes in its leverage ratio. Our modeling approach is similar to Collin-Dufresne and Goldstein's (2001) model, which in turn extends and corrects the paper by Longstaff and Schwartz (1995). In the above two studies, a stochastic risk-free interest rate, along with the stochastic firm's value, determine the pricing of risky bonds and corresponding credit (yield) spreads. In our model, the risk-free rate is assumed to be constant. We introduce a stochastic stock market index with the goal to study the impact of the business climate (as measured by the index performance) and the firm assets' beta on corporate bond prices. Our main assumptions are discussed below.

Assumption 1. The risk-free rate $r$ is constant for all maturities.

Assumption 1 is made solely for the purpose of keeping the model tractable. It is possible, however, to make it stochastic, but since the impact of stochastic interest rates on risky bond prices is well documented (see, for instance, CollinDufresne and Goldstein (2001) or Longstaff and Schwartz (1995)), we prefer not to do so.

Assumption 2. The uncertainty in the model is characterized by the probability space $(\Omega, \mathcal{F}, \mathcal{P})$, where $\Omega$ is the state space, $\mathcal{F}$ is the filtration, and $\mathcal{P}$ is the historical (true) probability measure.

Assumption 3. The total value of the firm's assets $V$ follows the diffusion process,

$$
\frac{d V_{t}}{V_{t}}=\left(\mu_{V}-\delta_{V}\right) d t+\sigma d W_{t},
$$

where $\mu_{V}$ is the instantaneous expected return and $\delta_{V}$ is the rate of all the firm's cash outflows per unit of time, $\sigma$ is the volatility of assets' returns, $\mu_{V}, \delta_{V}$, and $\sigma$ are all assumed to be positive constants, and $d W_{t}$ is the increment of a standard Wiener process under the true probability measure $\mathcal{P}$.

Assumption 4. There is a stock market index, and its value $I$ evolves as

$$
\frac{d I_{t}}{I_{t}}=\left(\mu_{I}-\delta_{I}\right) d t+\gamma d Z_{t},
$$

where $\mu_{I}$ is the expected drift, $\delta_{I}$ is the dividend yield, $\gamma$ is the volatility of the index returns, $\mu_{I}, \delta_{I}$, and $\gamma$ are all positive constants, and $d Z_{t}$ is the increment of a standard Wiener process under $\mathcal{P}$ such that $d W_{t} d Z_{t}=\rho d t$, where $\rho$ denotes the instantaneous correlation between the two Wiener processes.

One can think about the stock market index as a broadly diversified stock index (like the S\&P 500) or a sector- (industry-) specific index, depending upon whether the firm adjusts its leverage based on the market or the industry-specific business climate. 
Since the main goal of our paper is to derive risky bond prices and the corresponding credit spreads, we work with the risk-neutral probability measure instead of the historical one. Hence, we assume that:

Assumption 5. The financial market is frictionless and complete. Therefore, there exists a unique martingale probability measure $Q$ equivalent to $\mathcal{P}$.

Under the risk-neutral probability measure, the dynamics of the firm's value and the stock market index become

$$
\begin{aligned}
\frac{d V_{t}}{V_{t}} & =\left(r-\delta_{V}\right) d t+\sigma d W_{t}^{Q}, \\
\frac{d I_{t}}{I_{t}} & =\left(r-\delta_{I}\right) d t+\gamma d Z_{t}^{Q},
\end{aligned}
$$

where $W_{t}^{Q}=W_{t}+\rho \Lambda t, Z_{t}^{Q}=Z_{t}+\Lambda t$, and $\Lambda$ is the market price of risk. ${ }^{3}$

As in Collin-Dufresne and Goldstein (2001), it is convenient to define the $\log$-firm value and $\log$-index value variables: $y_{t}=\log V_{t}$ and $x_{t}=\log I_{t}$. Applying Ito's lemma, we obtain

$$
d y_{t}=\left(r-\delta_{V}-\frac{1}{2} \sigma^{2}\right) d t+\sigma d W_{t}^{Q},
$$

and

$$
d x_{t}=\left(r-\delta_{I}-\frac{1}{2} \gamma^{2}\right) d t+\gamma d Z_{t}^{Q} .
$$

As already mentioned, the performance of the stock market index is assumed to affect the firm's leverage ratio in our model. Therefore, we introduce the variable $\psi_{t}$, which refers to the "recent" performance of the stock market index,

$$
\psi_{t}=\log I_{t}-\log \bar{I}_{t}=x_{t}-\bar{x}_{t}
$$

where $\bar{x}_{t}=\log \bar{I}_{t}$ is the logarithm of the "historical average" value of the index. In our model, the variable $\psi_{t}$ aims to reflect the business climate: high values of $\psi$ (i.e., strong performance of the stock index) would imply economic improvements, and low values of $\psi$ (i.e., weak index performance) would imply economic slowdowns. We show below that the initial value of the stock index performance $\psi_{0}$ has an important impact on credit spreads.

The historical average value of the stock index is defined as

$$
\bar{I}_{t}=\exp \left(\theta \int_{-\infty}^{t} e^{-\theta(t-s)} x_{s} d s\right) .
$$

The above specification of the average historical index value implies that the latter is a geometric average of the past index values. ${ }^{4}$ The parameter $\theta$ represents

\footnotetext{
${ }^{3} \Lambda$ is equal to $\Lambda=\left(\mu_{I}-r\right) / \gamma$. Notice that despite the fact that we have two Wiener processes in the model, we have only one market price of risk defined above. The reason is that due to the assumed correlation between $W_{t}$ and $Z_{t}$, the Wiener process $W_{t}$ governing the uncertainty of the firm value can be decomposed into the market risk and the firm's idiosyncratic risk, which is not priced by the market.

${ }^{4}$ Formula (4) is a continuous-time analog to the definition of the geometric average,

$$
\bar{I}_{0}=I_{-n}^{\alpha_{n}} \cdot I_{-n+1}^{\alpha_{-n+1}} \cdot \ldots \cdot I_{0}^{\alpha_{0}}
$$
}


the weight with which the average is calculated: the higher the value of $\theta$, the more weight is put on the most recent history of the index. ${ }^{5}$ Also, notice that the setting of the lower integration limit in (4) to minus infinity grants us the Markovian property of the recent index performance variable $\psi_{t}{ }^{6}$

Using (4), we derive the dynamics of the market index performance,

$$
d \psi_{t}=d x_{t}-\theta \psi_{t} d t
$$

If we substitute in the above equation expression (3) for $d x_{t}$, we obtain

$$
d \psi_{t}=\theta\left(\frac{r-\delta_{i}-\frac{1}{2} \gamma^{2}}{\theta}-\psi_{t}\right) d t+\gamma d Z_{t}^{Q}, \quad \psi_{0}=\log \frac{I_{o}}{I_{0}} .
$$

Equation (5) implies that the performance of the stock market index follows a mean-reverting process. Also, we can see that the longer the time horizon during which the index performance is calculated, that is the smaller $\theta$, the higher is the long-run mean of the index performance and the lower is the speed of adjustment of the above mean-reverting process.

In further analysis, the $\log$-firm value, $y_{t}=\log V_{t}$, and the stock market index performance, $\psi_{t}=\log \left(I_{t} / \bar{I}_{t}\right)$, both determine the assumed dynamics of the firm's leverage ratio and the probability of default. First, we describe and motivate the specification of the leverage ratio process and second we present our modeling of the default event.

Assumption 6. The firm's $\log$-leverage ratio $l_{t}=\log \left(L_{t}\right)=\log \left(D_{t} / V_{t}\right)$, where $L_{t}$ is the firm's leverage ratio and $D_{t}$ is the book value of the firm's outstanding debt, evolves as

$$
d l_{t}=\lambda\left[\bar{l}^{Q}-\phi \psi_{t}-l_{t}\right] d t-\sigma d W_{t}^{Q}
$$

In Appendix A, we propose a book value of debt and a firm's equity specifications as well as debt and equity issuance policies that are consistent with the above dynamics of the firm's log-leverage ratio.

where $\sum \alpha_{i}=1$.

${ }^{5}$ To explain the role of $\theta$, assume that for a specific firm the relevant time horizon for the computation of the index performance is equal to one year. Then, by requiring values from the last one-year index to enter the historical average (4) with the cumulative weight of, for instance, 0.99 , we obtain

$$
\theta \int_{t-1}^{t} e^{-\theta(t-s)} d s=1-e^{-\theta}=0.99
$$

Solving the above equation, we obtain that the value of parameter $\theta$ should be equal to 4.6.

${ }^{6} \mathrm{We}$ can easily show that if in (4) one takes a finite lower boundary, for instance, $t-\bar{t}$, instead of $-\infty$ (with the appropriate adjustment of the weights), then at each point of time $t$ the innovations in $\psi_{t}$ will depend on the value of the index not only at time $t$, but also on its value at time $t-\bar{t}$. In that case, $\psi_{t}$ is non-Markovian and the further analysis becomes much more complex. For formula (4) to make sense, we have to define the "distant" history of the stock index. For example, we do not know the value of the S\&P 500 at time $t=-\infty$, or 500 years ago. Without loss of generality, we assume that at times prior to the appearance of the first data point of the index value, all the index values are equal to the initial index value. However, the distant index history can be irrelevant if one properly chooses the value of parameter $\theta$. For example, if $\theta=4.6$ (i.e., the performance of the index is calculated during the last one year), then the distant historical index values enter the average with a cumulative weight of 0.01 (see footnote 5). 
Equation (6) suggests that the firm's leverage ratio follows a mean-reverting process and that there is a negative relation between the stock market performance $\psi_{t}$ and changes in the leverage ratio, i.e., $\phi>0$. Such a formulation corresponds to the so-called trade-off theory of firms' capital structure, which builds on the notion of a target capital structure that balances costs and benefits of debt and equity (see, for example, Hovakimian et al. (2001) or Marsh (1982). Also, see the discussion in Section II). The above assumption also implies that the target, or long-run mean leverage ratio is time-dependent, equal to $l^{Q}-\phi \psi_{t}$ under the risk-neutral probability measure, and is negatively related to the stock market performance $\psi_{t}{ }^{7}$

To summarize, our modeling of the dynamics of the log-leverage ratio (6) is in line with the so-called trade-off theory of capital structure and is in line with studies of debt versus equity choice that find firms prefer to issue equity rather than debt, i.e., the leverage ratio tends to decline after periods of economic expansion (when $\psi_{t}$ is high) (see, for instance, Choe et al. (1993), Marsh (1982), and Taggart (1977)), and vice versa.

In our risk-neutral specification of the dynamics of the log-leverage (6), $\bar{l}^{Q}$ stands for the long-run mean log-leverage ratio when the firm is not concerned about timing of equity and debt issuances, i.e., when $\phi=0$. The risk-neutral value $l^{Q}$ and the true value $l$ of the long-run mean log-leverage ratio are related as

$$
\bar{l}^{Q}=\bar{l}+\frac{\sigma}{\lambda} \rho \Lambda,
$$

where $\Lambda$ is the market price of risk, $\sigma$ is the assets' volatility, and $\lambda$ is the speed of adjustment of the process in (6). We will use this relation in our numerical analysis to get an estimate of $\bar{l} Q$ from the historical (or true) values of the firm's target leverage ratios.

The diffusion term in (6) is derived from the definition of the leverage ratio and is based on the natural assumption that the firm's book value of debt evolves deterministically. ${ }^{8}$

For the sake of completeness, we would like to point out that Collin-Dufresne and Goldstein (2001), who have a stochastic short-term risk-free interest rate as a second factor, derive similar dynamics of the log-leverage ratio endogenously. Their derivation is based on the assumed negative relation between the firm's default threshold and the level of interest rates, where the default threshold is implicitly associated with the firm's book value of debt. Therefore, it follows from their model that changes in the firm's leverage are due to changes in the firm's assets value and in the firm's debt issuance policy, where the latter is influenced by changes in the interest rate. In contrast, our model explains changes in the firm's leverage ratio by the firm's equity and debt issuance policies, which are in turn affected by the stage of the business cycle.

\footnotetext{
${ }^{7}$ For example, Fama and French (2002) find a negative relation between target market and book leverage and the firm's asset returns, and this is in line with our assumption given a positive correlation between assets and index returns.

${ }^{8}$ The market value of the risky debt may evolve stochastically, but the book value of debt, as follows from its definition, evolves deterministically in our framework. Assuming that $d \log D_{t}=$ $g\left(t, y_{t}, \psi_{t}\right) d t$, and then using the definition of the log-leverage, i.e., $l_{t}=\log \left(D_{t} / V_{t}\right)=\log D_{t}-y_{t}$, we obtain that the diffusion term of $d l_{t}$ is equal to $-\sigma d W_{t}^{Q}$.
} 
Finally, we outline one important property of the variance of the log-leverage ratio $l_{t}$ in Proposition 1. This property will help us explain the impact of the firm's assets beta on credit spreads in Section V.

Proposition 1. The variance of the log-leverage ratio, $\operatorname{Var}_{0}\left[l_{t}\right]$, increases with the correlation between the asset and the stock index returns if $0<\lambda<\theta$ and the parameters $\phi, \sigma$, and $\gamma$ are all positive.

\section{Proof. See Appendix B.}

Existing structural models define the event of default in two distinct ways. For example, in Merton (1974) the firm defaults if, at the time of maturity of the bond, the value of the firm's assets is below the face value of the bond. In Longstaff and Schwartz (1995) and Collin-Dufresne and Goldstein (2001), default occurs when the firm's assets decline to an exogenously specified boundary (threshold). On the other hand, Leland (1994) and Leland and Toft (1996) model a firm that defaults strategically and, by maximizing the firm's equity, they derive the default boundary endogenously.

In this paper, we assume a very general firm's debt structure consisting of different bonds with different maturities. The total time- $t$ book value of the firm's outstanding debt is denoted by $D_{t}$, and we specify the default event as:

Assumption 7. The firm defaults when the value of its assets $V$ hits an endogenously determined boundary (threshold) for the first time. This threshold is assumed to be equal to the firm's book value of total debt $D$. Equivalently, default occurs when the firm's log-leverage ratio $l_{t}$ reaches zero for the first time. The corresponding stopping time is defined as

$$
\tilde{\tau}=\inf \left\{t>0, V_{t}=D_{t} \Leftrightarrow l_{t}=\log \frac{D_{t}}{V_{t}}=0\right\} .
$$

The firm continues to service its debt as long as the value of its assets $V_{t}$ is greater than the book value of its debt $D_{t}$. If $V$ hits $D$, the firm is assumed either to be unable to meet some of its debt obligations or to violate minimum net worth or working capital requirements. The firm is then assumed to default on all its debt obligations because of, for instance, cross-default provisions. Although we assume that the default boundary is equal to the book value of debt, we could extend our analysis to allow the default threshold to be, for example, a linear function of $D .{ }^{9}$ However, since it is the leverage ratio, rather than the actual value of the default boundary, that plays a major role in our analysis, allowing a linear specification of the default boundary will not add any new insights into the valuation of the risky bond.

To price a risky bond, we have to specify its payoff in case of default. Namely, we must specify how much a bondholder recovers when the firm is in distress. In order to keep our model simple, we assume that, in the case of de-

\footnotetext{
${ }^{9}$ For example, in Moody's KMV model, the default boundary is equal to the sum of the face value of the short-term debt and half of the face value of the long-term debt. In Huang and Huang (2002), the default boundary is equal to $60 \%$ of the book value of a firm's debt. However, they report that their estimated credit spreads do not change significantly when they change the default boundary to $100 \%$ of the book value of debt (table 12 in Huang and Huang (2002)).
} 
fault, a bondholder recovers a constant fraction of the face value of the risky bond, ${ }^{10}$ and we set this fraction exogenously. ${ }^{11}$

Assumption 8. Following Longstaff and Schwartz (1995), we assume that in the case of default each bondholder receives $(1-w)$ units of the identical risk-free bond (i.e., with the same face value and maturity) in exchange for the defaulted risky bond at the time of default.

Assumption 8 implies that at the time of maturity of a risky bond, an investor will recover only a fraction $(1-w)$ of the face value of his risky bond, where the factor $w$ represents a loss given default fraction of the face value of the defaulted security. ${ }^{12}$

\section{Pricing Corporate Bonds}

Based on Assumption 8 and given that the default-free interest rate $r$ is constant, we use risk-neutral valuation to price a zero-coupon corporate bond that promises to pay one dollar at time $T$,

$$
B(0, T)=e^{-r T} E_{0}^{Q}\left[\mathbf{1}_{\tilde{\tau}>T}+(1-w) \mathbf{1}_{\tilde{\tau} \leq T}\right],
$$

where $(1-w)$ is a constant recovery rate in case of default. The above pricing formula can be rewritten in the form,

$$
B(0, T)=e^{-r T}\left(1-w Q\left(l_{0}, T\right)\right),
$$

where $Q\left(l_{0}, T\right)$ is the risk-neutral probability that default occurs before time $T$, where the event of default is defined in Assumption 7. To define the probability of default, we have to estimate the hitting time density function of the process governing the dynamics of the log-leverage ratio $l_{t}$. From (6), it follows that $l_{t}=l_{t}\left(\psi_{t}, W_{t}\right)$ is a two-factor Markov process, and there is no known closed-form solution for the density of the hitting time for such a process. Therefore, we derive the risk-neutral probability of default $Q\left(l_{0}, T\right)$ numerically by using the technique proposed by Collin-Dufresne and Goldstein (2001) (see their proposition 2).

Proposition 2. Given the initial value of the firm's log-leverage $l_{0}^{Q}$ and the initial distance between the current and the average index value $\psi_{0}$, the risk-neutral probability that default occurs before maturity of the bond $T$ is equal to

$$
Q\left(\psi_{0}, l_{0}^{Q}, T\right)=\sum_{i=1}^{N_{\psi}} \sum_{j=1}^{N_{T}} q\left(\psi_{i}, t_{j}\right),
$$

\footnotetext{
${ }^{10}$ One could also assume a more complex structure of the recovery rate. For example, the recovery rate can depend on the bond's seniority, which would imply that the strict absolute priority rule (APR) holds. However, empirical evidence shows that the APR is frequently violated. For example, Franks and Torous (1989) and Weiss (1990) find that the APR is violated in about $75 \%$ of the bankruptcies they study.

${ }^{11}$ Several studies model the recovery rate as the outcome of the bargaining between different corporate claim holders. See, for example, Anderson and Sundaresan (1996).

${ }^{12}$ Following Merton (1974), we could extend our model to treat the recovery value as a constant fraction of the value of the firm's assets at the time of default. Also, one can make the recovery rate time-dependent to reflect bonds' seniority levels or to reflect the recovery rate's dependence with respect to the business cycle variable (see Altman, Brady, Resti, and Sironi (2002)).
} 
where

$$
\begin{aligned}
q\left(\psi_{i}, t_{1}\right) & =\Delta \psi G\left(\psi_{i}, t_{1}\right) \quad i=1,2, \ldots, N_{\psi} \\
q\left(\psi_{i}, t_{j}\right) & =\Delta \psi\left[G\left(\psi_{i}, t_{j}\right)-\sum_{v=1}^{j-1} \sum_{u=1}^{N_{\psi}} q\left(\psi_{u}, t_{v}\right) g\left(\psi_{i}, t_{j}, \psi_{u}, t_{v}\right)\right] \\
i=1, \ldots, N_{\psi} \quad \text { and } \quad j=2, \ldots, N_{T} & \\
G(\psi, t) & \equiv \pi\left(\psi_{t}, \psi_{0}\right) N\left(\frac{\mu\left(\psi_{t}, t, l_{0}^{Q}, \psi_{0}\right)}{\Sigma\left(\psi_{t}, t, l_{0}^{Q}, \psi_{0}\right)}\right) \\
g\left(\psi_{t}, t, \psi_{s}, s\right) & \equiv \pi\left(\psi_{t}, t, \psi_{s}, s\right) N\left(\frac{\mu\left(\psi_{t}, t, l_{s}=0, \psi_{s}, s\right)}{\Sigma\left(\psi_{t}, t, l_{s}=0, \psi_{s}, s\right)}\right) \quad \forall t>s,
\end{aligned}
$$

where $\pi\left(\psi_{t}, t, \psi_{s}, s\right)$ is the transition density of the process $\psi_{t}, \mu$ and $\Sigma$ are the conditional mean and the variance of the log-leverage, respectively, and $\Delta \psi$ and $\Delta t$ are discretization intervals.

Proof. See Appendix C.

Based on the theoretical bond prices defined in equation (9), we can compute the term structure of credit spreads $\left(S_{T}\right)$ using the expression,

$$
S_{T}=-\frac{\log B(0, T)}{T}-r
$$

In Section V, we present numerically simulated credit spreads and analyze their sensitivities to the main parameters of the model. We also compare the credit spreads generated by our model to actual credit spreads and to those derived from other well-known structural corporate debt pricing models.

\section{Numerical Results}

In this section, we analyze the performance of our model numerically. First, we compare term structures of credit spreads generated by our model to those derived from the Longstaff and Schwartz (1995), Collin-Dufresne and Goldstein (2001), and Merton (1974) models. For that purpose, we compute credit spreads for representative firms from different investment grade groups (firms are grouped using Moody's credit ratings: Aaa, Aa, A, Baa, and Ba) and compare them with observed market yield spreads. Next, we study the sensitivity of the credit spreads to the initial leverage ratio, the stock index performance, the speed of adjustment of the log-leverage ratio, and the firm's assets beta.

We begin with the description of the model's base case parameter values that are based either on market data or on estimates reported in prior empirical studies.

\section{A. The Base Case Parameters}

Base Case Parameters. Assets' return volatility, $\sigma(0.30)$; Stock market index return volatility, $\gamma(0.20)$; Risk-free rate, $r(0.03)$; Dividend yields, $\delta_{V}=\delta_{I}(0.01)$; 
Unitary market price of risk, $\Lambda$ (0.2); Firm's assets beta, $\beta$ (0.75); Speed of adjustment, $\lambda(0.05)$; Recovery rate, $(1-w)(0.51)$; Parameter $\theta$ (see equation (4)) (2); Parameter $\phi$ (see equation (6)) (10).

We set the value of the assets' volatility $\sigma$ to 0.30 . We take this value exogenously, however, it is close to the implied volatility values obtained by Huang and Huang (2002). They derive values for the assets' volatility endogenously by calibrating the Longstaff and Schwartz (1995) and Collin-Dufresne and Goldstein (2001) models. The S\&P 500 index is taken as a proxy for the market index. Using monthly time-series data for the S\&P 500, collected from Datastream, we estimate that the annualized standard deviation of the index returns during 19992002 was close to $20 \%$. Thus, we set $\gamma=0.20$. The risk-free rate $r$ is assumed to be $3 \%$, since this figure is close to the average of Treasury note yields during the period 1999-2002. Both the assets' payout ratio $\delta_{V}$ and the index dividend yield $\delta_{I}$ are assumed to be equal to $1.0 \%$. In our analysis, estimates of the expected assets and index returns, $\mu_{V}$ and $\mu_{I}$, respectively, are not required. Instead, we need an estimate of the unitary market price of risk $\Lambda$, which is equal to the ratio of the market risk premium to the market returns volatility. In our base case, we set $\Lambda$ equal to 0.2 . This value is within the range of the estimated market price of risk in Lustig (2002), who studied the impact of liquidity shocks on the market price of risk. The value of the firm's beta is set to $\beta=0.75$, which is close to the estimated average of the credit rating groups' betas by Barnhill and Maxwell (2002). ${ }^{13}$ Thus, the correlation coefficient $\rho$ is derived from the relation $\beta=(\sigma / \gamma) \rho$ and is equal to $\rho=0.5$.

The base case value of parameter $\lambda$ (see equation (6)), denoting the speed of adjustment of the log-leverage ratio to its long-term mean value, is set to $0.05 .{ }^{14}$ However, we will study the sensitivity of credit spreads with respect to changes in the speed of adjustment $\lambda$. Values of historical (true) target leverage ratios $L$ are taken from Standard \& Poor's (2002) and displayed in Table 2. The risk-neutral log-leverage ratios are then defined by using formula (7).

TABLE 2

Target Leverage Ratios

Table 2 shows the base case values for the target leverage ratios. The data are from Standard \& Poor's (2002) and correspond to the three-year (1998-2000) median U.S. industrial long-term debt to capital ratios.

\begin{tabular}{llllll}
\cline { 2 - 2 } & $\frac{\mathrm{Aaa}}{0.133}$ & $\frac{\mathrm{Aa}}{0.282}$ & $\frac{\mathrm{A}}{0.399}$ & $\frac{\mathrm{Baa}}{0.425}$ & $\frac{\mathrm{Ba}}{0.572}$ \\
\hline
\end{tabular}

The recovery rate $(1-w)$ is taken from Huang and Huang (2002) and is equal to 0.51 . This value is consistent with observed recovery rates. ${ }^{15}$ The initial value of the index performance $\psi_{0}$ (see equation (5)) is assumed to be 0.2 . Given that

\footnotetext{
${ }^{13}$ Barnhill and Maxwell (2002) assess the value-at-risk of a portfolio of fixed income securities with correlated interest rate, credit, and exchange rate risk. For each credit rating group, they estimate an average beta in order to derive the corresponding cost of equity.

${ }^{14}$ This value is close to Fama and French's (2002) estimate, $\lambda \approx 0.1$.

${ }^{15}$ For example, see Altman et al. (2002) who find that recovery rates of defaulted bonds vary between $25 \%$ and $65 \%$.
} 
the influence of this parameter on estimated credit spreads is quite significant, we will study the impact of the initial index performance on the level of credit spreads. The initial true leverage ratio $L_{0}$ is assumed to be equal to $80 \%$ of the target leverage ratio, i.e., $L_{0}=0.8 \bar{L}$. In the second part of our numerical study, we will show that changes in the initial leverage ratio have a significant impact on credit spreads. The value of parameter $\theta$ (see equation (4)), which models the length of a time period during which the index performance is calculated, is equal to 2. This value implies that the performance of the stock market index is computed over the previous 2.5 years.

\section{B. Comparison with Other Structural Models}

In Table 3, we compare the explanatory power of our model with the Longstaff and Schwartz (1995), Collin-Dufresne and Goldstein (2001), and Merton (1974) structural models. To make this comparison, we run our model under the same parameter values (which are common to all models) as in Huang and Huang (2002). Namely, we set the risk-free rate to $r=8 \%$, the assets' payout ratio $\delta_{V}$ and the index dividend yield $\delta_{I}$ to $6 \%$, and the recovery rate at default to $51.31 \%$. In each credit rating group, the initial leverage ratio in our model is equal to $80 \%$ of the corresponding target leverage ratio, where the latter corresponds to the target leverage value in Huang and Huang (2002). ${ }^{16}$ For each credit rating group, we take the assets' volatility value $\sigma=30 \%$, which is close to the average of implied volatilities from Huang and Huang (for the Longstaff and Schwartz (with stochastic interest rate) and Collin-Dufresne and Goldstein models). The default boundary equals $80 \%$ of the firm's face value of total debt. The values of those parameters that are not present or defined in Huang and Huang (2002) correspond to our base case choice. We compare credit spreads generated by the four models to the actual market yield spreads taken from Huang and Huang.

We can see that for the same subset of parameters, our model explains actual credit spreads better than the Longstaff and Schwartz, Collin-Dufresne and Goldstein, and Merton models for most investment grade bonds with all maturities (except four-year Aaa and Aa bonds). For example, for four-year Baa and Ba bonds, our model explains $60.5 \%$ and $62.1 \%$, respectively, of the average market corporate yield spreads, whereas the Collin-Dufresne and Goldstein model explains only $19.7 \%$ and $52.5 \%$, respectively. The explanatory power of our model is even higher for 10-year bonds. Indeed, for those bonds, our model significantly outperforms the other credit risk models across all credit rating groups (except Aaa bonds). For example, for 10-year A-rated bonds, we explain 53.9\% of the average market spread, and the best results of the other models are $26.3 \%$ (Merton model) and $18.3 \%$ (Collin-Dufresne and Goldstein model). The performance of our model is even more pronounced for the lower credit rating groups. This comparison suggests that when choosing among two-factor structural models to price corporate bonds, the evolution of the business climate (as proxied by the recent performance of a stock market index) is more important than the consideration of stochastic interest rates.

\footnotetext{
${ }^{16}$ Notice that setting the initial leverage ratio to $80 \%$ sets our model at a disadvantage (relative to the $100 \%$ level), since credit spreads increase with the initial leverage ratio (see Table 8 ).
} 


\section{TABLE 3}

The Comparison of the Performance of Structural Models

\begin{tabular}{|c|c|c|c|c|c|}
\hline & Ааа & Aa & A & Baа & $\mathrm{Ba}$ \\
\hline & \multicolumn{5}{|c|}{ Time to Maturity: $T=4$} \\
\hline \multirow[t]{2}{*}{ Average Market Yield Spread } & 55 & & & 158 & 320 \\
\hline & \multicolumn{5}{|c|}{$\%$ of Spreads Due to Default } \\
\hline Demchuk and Gibson model & $0.3 \%$ & $5.3 \%$ & $28.8 \%$ & $60.5 \%$ & $62.1 \%$ \\
\hline Longstaff and Schwartz model & $1.5 \%$ & $7.0 \%$ & $7.8 \%$ & $16.1 \%$ & $46.6 \%$ \\
\hline Collin-Dufresne and Goldstein model & $0.1 \%$ & $9.7 \%$ & $10.3 \%$ & $19.7 \%$ & $52.5 \%$ \\
\hline \multirow[t]{2}{*}{ Merton model } & $0.2 \%$ & $1.1 \%$ & $5.0 \%$ & $21.0 \%$ & $65.5 \%$ \\
\hline & \multicolumn{5}{|c|}{ Time to Maturity: $T=10$} \\
\hline \multirow[t]{2}{*}{ Average Market Yield Spread } & 63 & 91 & 123 & 194 & 320 \\
\hline & \multicolumn{5}{|c|}{$\%$ of Spreads Due to Default } \\
\hline Demchuk and Gibson model & $3.0 \%$ & $17.6 \%$ & $53.9 \%$ & $77.3 \%$ & $74.5 \%$ \\
\hline Longstaff and Schwartz model & $9.6 \%$ & $9.4 \%$ & $11.8 \%$ & $19.9 \%$ & $48.1 \%$ \\
\hline Collin-Dufresne and Goldstein model & $18.2 \%$ & $16.4 \%$ & $18.3 \%$ & $26.9 \%$ & $57.1 \%$ \\
\hline Merton model & $11.9 \%$ & $16.6 \%$ & $26.3 \%$ & $41.6 \%$ & $73.6 \%$ \\
\hline
\end{tabular}

\section{Sensitivity Analysis}

In Table 4, we present credit spreads implied by our model under the base case parameter values. The table shows that our model yields increasing term structures of credit spreads for Aaa, Aa, A, and Ba bonds. For Baa bonds, we obtain a humped term structure due to our parameters' specification. It is worthwhile to mention that every term structure of credit spreads derived from a diffusionbased structural credit risk model becomes humped at a specific maturity date due to the decreasing long-term marginal probability of default.

The continuity of the assets' value dynamics yields negligible default probabilities for short maturity bonds and for highly rated bonds of all maturities. For example, in our case the long-term leverage ratio of Aaa-rated firms equals 0.13, and these firms, according to our modeling of the leverage dynamics, balance their leverage ratios around this value. Therefore, given the continuity of their assets value, the probability of default (i.e., the probability that the leverage ratio approaches unity) for Aaa firms is almost negligible and, hence, so are credit spreads. We would like to mention that this underestimation is common to all structural models of default that model the dynamics of the assets value as a continuous diffusion process. However, this effect can be corrected if, for instance, one introduces jumps in the assets value process (see Zhou (2001)). Also, a nonnegligible part of actual yield spreads can be explained by liquidity risk, whereas our model aims to study the sole contribution of default risk to yield spreads. 
TABLE 4

Credit Spreads under the Base Case Parameter Values

Table 4 shows credit spreads (in basis points) resulting from this paper's model under the base case parameters choice (see Subsection A of Section V). For each credit rating group, the initial leverage ratio $L_{0}$ is equal to 0.8 times the corresponding target leverage ratio (the target leverage ratios are defined in Table 2).

\begin{tabular}{|c|c|c|c|c|c|}
\hline Time to Maturity & Aaa & $\mathrm{Aa}$ & A & Baa & $\mathrm{Ba}$ \\
\hline$T=1$ & 0.00 & 0.00 & 0.07 & 1.44 & 39.39 \\
\hline$T=4$ & 0.32 & 21.94 & 48.99 & 116.92 & 305.42 \\
\hline$T=7$ & 4.06 & 58.90 & 98.44 & 172.39 & 321.85 \\
\hline$T=10$ & 10.33 & 81.21 & 120.75 & 186.13 & 300.84 \\
\hline
\end{tabular}

The objective of the second part of our numerical analysis is to point out through sensitivity analysis some non-standard features of our corporate bond pricing model.

\section{The Impact of the Stock Index Performance $\left(\psi_{0}\right)$ on Credit Spreads}

In Table 5, we report resulting credit spreads under different values of the performance of the stock market index $\psi_{0}$. We see that credit spreads tend to decrease with $\psi_{0}$. This relation suggests that credit spreads are lower when the recent performance of the stock index is high, and that they are higher when the stock index performance is low. Thus, our two-factor model generates credit spreads that are in line with the empirically observed tendency of credit spreads to be lower during economic expansions and higher during recessions.

TABLE 5

The Impact of the Stock Index Performance $\left(\psi_{0}\right)$ on Credit Spreads

Table 5 shows credit spreads (in basis points) resulting from this paper's model when the performance of the stock market index equals $50 \%, 20 \%$ (base case), and $-50 \%$. The other parameters are base case ones (see Subsection A of Section $\mathrm{V})$.

\begin{tabular}{|c|c|c|c|c|c|}
\hline & Aaa & $\mathrm{Aa}$ & A & Baa & $\mathrm{Ba}$ \\
\hline & \multicolumn{5}{|c|}{ Time to Maturity: $T=1$} \\
\hline $\begin{array}{l}\psi(0)=0.5 \\
\psi(0)=0.2 \text { (base) } \\
\psi(0)=-0.5\end{array}$ & $\begin{array}{l}0.0 \\
0.0 \\
0.0\end{array}$ & $\begin{array}{l}0.0 \\
0.0 \\
0.0\end{array}$ & $\begin{array}{l}0.0 \\
0.1 \\
0.5\end{array}$ & $\begin{array}{l}0.6 \\
1.4 \\
7.9\end{array}$ & $\begin{array}{r}21.4 \\
39.4 \\
140.2\end{array}$ \\
\hline$\psi(0)=-0.5$ & \multicolumn{5}{|c|}{ Time to Maturity: $T=4$} \\
\hline $\begin{array}{l}\psi(0)=0.5 \\
\psi(0)=0.2 \text { (base) } \\
\psi(0)=-0.5\end{array}$ & $\begin{array}{l}0.2 \\
0.3 \\
0.8\end{array}$ & $\begin{array}{l}16.2 \\
21.9 \\
42.6\end{array}$ & $\begin{array}{l}37.3 \\
49.0 \\
88.9\end{array}$ & $\begin{array}{r}92.3 \\
116.9 \\
196.0\end{array}$ & $\begin{array}{l}251.6 \\
305.4 \\
464.1\end{array}$ \\
\hline$\psi(0)=-0.5$ & \multicolumn{5}{|c|}{ Time to Maturity: $T=7$} \\
\hline $\begin{array}{l}\psi(0)=0.5 \\
\psi(0)=0.2 \text { (base) } \\
\psi(0)=-0.5\end{array}$ & $\begin{array}{l}3.2 \\
4.1 \\
7.0\end{array}$ & $\begin{array}{l}49.6 \\
58.9 \\
86.5\end{array}$ & $\begin{array}{r}84.2 \\
98.4 \\
139.6\end{array}$ & $\begin{array}{l}150.1 \\
172.4 \\
234.8\end{array}$ & $\begin{array}{l}286.5 \\
321.8 \\
416.0\end{array}$ \\
\hline$\psi(0)=-0.5$ & \multicolumn{5}{|c|}{ Time to Maturity: $T=10$} \\
\hline $\begin{array}{l}\psi(0)=0.5 \\
\psi(0)=0.2 \text { (base) } \\
\psi(0)=-0.5\end{array}$ & $\begin{array}{r}8.8 \\
10.3 \\
15.0\end{array}$ & $\begin{array}{r}72.0 \\
81.2 \\
106.5\end{array}$ & $\begin{array}{l}108.2 \\
120.7 \\
154.8\end{array}$ & $\begin{array}{l}168.8 \\
186.1 \\
232.1\end{array}$ & $\begin{array}{l}277.0 \\
300.8 \\
361.6\end{array}$ \\
\hline
\end{tabular}




\section{The Impact of the Speed of Adjustment of the Log-Leverage Process $\lambda$ on Credit Spreads}

In Table 6, we report credit spreads for different values of the parameter $\lambda$, the speed of adjustment of the mean-reverting process (6) governing the dynamics of the log-leverage ratio. Changes in the speed of adjustment may have a twosided effect on credit spreads. On the one side, when the speed of adjustment is low, one would expect the firm's leverage ratio to exhibit higher variation around the target leverage ratio than when the speed is high. This implies that slower mean reversion leads to higher volatility of the leverage ratio and, hence, to higher credit spreads. On the other hand, when the initial leverage ratio is below the target one, a lower speed of adjustment of the leverage ratio implies that the latter will converge to its higher target level more slowly and, hence, credit spreads should decrease. We can see that these two effects indeed take place when the initial leverage ratio equals $80 \%$ of the target level (Panel A, Table 6). For most bonds, credit spreads tend to widen when the speed of adjustment decreases from 0.15 to 0.015 , and that means that the first effect dominates the second one. Only for seven- and 10-year Ba bonds does the second effect dominate the first one. However, when the initial leverage ratio is set equal to the target level (Panel B, Table 6), then only the first effect is present and, hence, credit spreads widen when the speed of adjustment decreases.

\section{The Impact of the Assets Beta $(\beta)$ on Credit Spreads}

In our model, the firm's assets beta $(\beta)$ noticeably affects credit spreads. Table 7 and Figure 1 show that credit spreads widen when the firm's beta coefficient increases, and that this effect is particularly strong (in relative terms) for short maturity bonds. To explain the positive relation between credit spreads and the firm's assets beta, we refer to Proposition $1 .{ }^{17}$ Also, we would like to mention that the beta effect on credit spreads is slightly stronger for lower credit rating groups ( $\mathrm{Baa}$ and $\mathrm{Ba}$ ) and is weaker for higher credit rating groups (Aa and $\mathrm{A}$ ) (see Figure 1). The dependence of credit spreads on the firm's assets beta explains why bonds with similar credit ratings but in different industries or sectors can yield different credit spreads.

\section{The Impact of the Firm's Initial Leverage $\left(L_{0}\right)$ on Credit Spreads}

The firm's initial leverage ratio $\left(L_{0}\right)$ is one of the factors that plays a crucial role in bond pricing and, hence, in the determination of initial credit spreads. ${ }^{18}$ This factor is a kind of "distance to default" measure. Intuitively, the higher is the initial leverage, the smaller is the distance to default and, thus, the higher is the probability that the firm will be in distress during a given time horizon. This, in turn, induces higher credit spreads. Indeed, credit spreads of lower grade bonds, which are characterized by high leverage ratios, are much higher than those of high grade bonds, whose leverage ratios are low. Our model fully confirms this

\footnotetext{
${ }^{17}$ Our base case parameters satisfy the conditions of Proposition 1 . Therefore, the correlation between the assets and index returns and, hence, the firm's assets beta positively influences the volatility of the log-leverage ratio and the level of the credit spreads.

${ }^{18} L_{0}$ enters the model through the relation $l_{0}=\log \left(L_{0}\right)$ (see equation (6)).
} 
TABLE 6

The Impact of the Speed of Adjustment of the Log-Leverage Process $(\lambda)$ on Credit Spreads

Table 6 shows credit spreads (in basis points) resulting from this paper's model when the speed of adjustment of the log-leverage process (6) equals $\lambda=0.15, \lambda=0.05$ (base case), and $\lambda=0.015$. The other parameters are base case ones (see Subsection A of Section V).

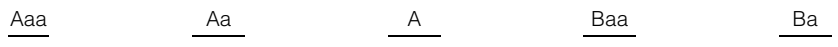

Panel A. Initial Leverage Ratio is $80 \%$ of the Target Leverage Ratio

Time to Maturity: $T=1$

\begin{tabular}{|c|c|c|c|c|c|}
\hline$\lambda=0.15$ & 0.0 & 0.0 & 0.1 & 1.6 & 35.9 \\
\hline$\lambda=0.05$ (base) & 0.0 & 0.0 & 0.1 & 1.4 & 39.4 \\
\hline \multirow[t]{2}{*}{$\lambda=0.015$} & 0.0 & 0.0 & 0.1 & 1.5 & 42.8 \\
\hline & \multicolumn{5}{|c|}{ Time to Maturity: $T=4$} \\
\hline$\lambda=0.15$ & 0.3 & 23.2 & 51.6 & 122.2 & 314.3 \\
\hline$\lambda=0.05$ (base) & 0.3 & 21.9 & 49.0 & 116.9 & 305.4 \\
\hline \multirow[t]{2}{*}{$\lambda=0.015$} & 0.4 & 23.4 & 51.3 & 120.7 & 311.3 \\
\hline & \multicolumn{5}{|c|}{ Time to Maturity: $T=7$} \\
\hline$\lambda=0.15$ & 2.6 & 54.9 & 97.2 & 178.8 & 344.8 \\
\hline$\lambda=0.05$ (base) & 4.1 & 58.9 & 98.4 & 172.4 & 321.8 \\
\hline \multirow[t]{2}{*}{$\lambda=0.015$} & 5.6 & 64.7 & 104.3 & 176.6 & 320.6 \\
\hline & \multicolumn{5}{|c|}{ Time to Maturity: $T=10$} \\
\hline$\lambda=0.15$ & 5.3 & 73.2 & 118.1 & 195.6 & 331.5 \\
\hline$\lambda=0.05$ (base) & 10.3 & 81.2 & 120.7 & 186.1 & 300.8 \\
\hline$\lambda=0.015$ & 15.0 & 89.4 & 127.3 & 188.4 & 294.7 \\
\hline \multicolumn{6}{|c|}{ Panel B. Initial Leverage Ratio is Equal to the Target Leverage Ratio } \\
\hline & \multicolumn{5}{|c|}{ Time to Maturity: $T=1$} \\
\hline$\lambda=0.15$ & 0.0 & 0.1 & 1.1 & 13.4 & 186.2 \\
\hline$\lambda=0.05$ (base) & 0.0 & 0.1 & 1.2 & 16.8 & 255.4 \\
\hline \multirow[t]{2}{*}{$\lambda=0.015$} & 0.0 & 0.1 & 1.4 & 19.5 & 295.9 \\
\hline & \multicolumn{5}{|c|}{ Time to Maturity: $T=4$} \\
\hline$\lambda=0.15$ & 0.8 & 42.1 & 88.5 & 196.5 & 467.6 \\
\hline$\lambda=0.05$ (base) & 1.1 & 49.8 & 102.3 & 221.9 & 517.5 \\
\hline \multirow[t]{2}{*}{$\lambda=0.015$} & 1.4 & 57.4 & 115.0 & 242.7 & 551.0 \\
\hline & \multicolumn{5}{|c|}{ Time to Maturity: $T=7$} \\
\hline$\lambda=0.15$ & 4.0 & 76.0 & 130.6 & 232.5 & 430.0 \\
\hline$\lambda=0.05$ (base) & 7.9 & 94.7 & 151.7 & 252.8 & 444.2 \\
\hline \multirow[t]{2}{*}{$\lambda=0.015$} & 11.7 & 109.9 & 169.0 & 270.7 & 459.5 \\
\hline & \multicolumn{5}{|c|}{ Time to Maturity: $T=10$} \\
\hline$\lambda=0.15$ & 7.2 & 90.9 & 143.9 & 233.0 & 382.9 \\
\hline$\lambda=0.05$ (base) & 16.4 & 113.6 & 164.2 & 244.8 & 379.1 \\
\hline$\lambda=0.015$ & 25.2 & 130.9 & 180.6 & 257.7 & 384.7 \\
\hline
\end{tabular}

intuition. In Table 8, we compare credit spreads when the initial leverage ratio is set to $80 \%$ (the base case), $100 \%$, and $120 \%$ of the target leverage ratio. We see that this increase in the initial leverage induces credit spreads to become substantially higher. Also, we see that short maturity bonds are much more sensitive to changes in the initial leverage ratio than long maturity bonds. Namely, a given increase in the initial leverage ratio induces credit spreads to at least double for bonds with a maturity of up to four years. This difference in sensitivities of short and long maturity bonds to the initial leverage is due to the mean reversion of the leverage ratio and the independence of the long-run mean leverage from its initial level (see equation (6)). 


\section{TABLE 7}

\section{The Impact of the Assets Beta $(\beta)$ on Credit Spreads}

Table 7 shows credit spreads (in basis points) resulting from this paper's model when the assets beta equals $\beta=1.25$ $\beta=0.75$ (base case), and $\beta=-0.75$. The other parameters are base case ones (see Subsection A of Section $\mathrm{V}$ ).

\begin{tabular}{|c|c|c|c|c|c|}
\hline & Aaa & $\mathrm{Aa}$ & A & Baa & $\mathrm{Ba}$ \\
\hline & \multicolumn{5}{|c|}{ Time to Maturity: $T=1$} \\
\hline$\beta=1.25$ & 0.0 & 0.0 & 0.1 & 2.5 & 55.7 \\
\hline$\beta=0.75$ (base) & 0.0 & 0.0 & 0.1 & 1.4 & 39.4 \\
\hline \multirow[t]{2}{*}{$\beta=-0.75$} & 0.0 & 0.0 & 0.0 & 0.2 & 10.4 \\
\hline & \multicolumn{5}{|c|}{ Time to Maturity: $T=4$} \\
\hline$\beta=1.25$ & 0.8 & 35.9 & 73.5 & 159.7 & 375.5 \\
\hline$\beta=0.75$ (base) & 0.3 & 21.9 & 49.0 & 116.9 & 305.4 \\
\hline \multirow[t]{2}{*}{$\beta=-0.75$} & 0.0 & 2.5 & 8.1 & 29.5 & 123.7 \\
\hline & \multicolumn{5}{|c|}{ Time to Maturity: $T=7$} \\
\hline$\beta=1.25$ & 8.4 & 87.8 & 137.4 & 223.7 & 384.1 \\
\hline$\beta=0.75$ (base) & 4.1 & 58.9 & 98.4 & 172.4 & 321.8 \\
\hline \multirow[t]{2}{*}{$\beta=-0.75$} & 0.1 & 9.3 & 21.0 & 51.6 & 141.9 \\
\hline & \multicolumn{5}{|c|}{ Time to Maturity: $T=10$} \\
\hline$\beta=1.25$ & 19.6 & 116.2 & 163.1 & 235.7 & 352.9 \\
\hline$\beta=0.75$ (base) & 10.3 & 81.2 & 120.7 & 186.1 & 300.8 \\
\hline$\beta=-0.75$ & 0.5 & 14.6 & 28.4 & 59.5 & 137.6 \\
\hline
\end{tabular}

\section{FIGURE 1}

The Impact of the Assets Beta $(\beta)$ on Credit Spreads

Figure 1 shows four-year credit spreads (in basis points) resulting from this paper's model as a function of the assets beta The other parameters are base case ones (see Subsection A of Section V).

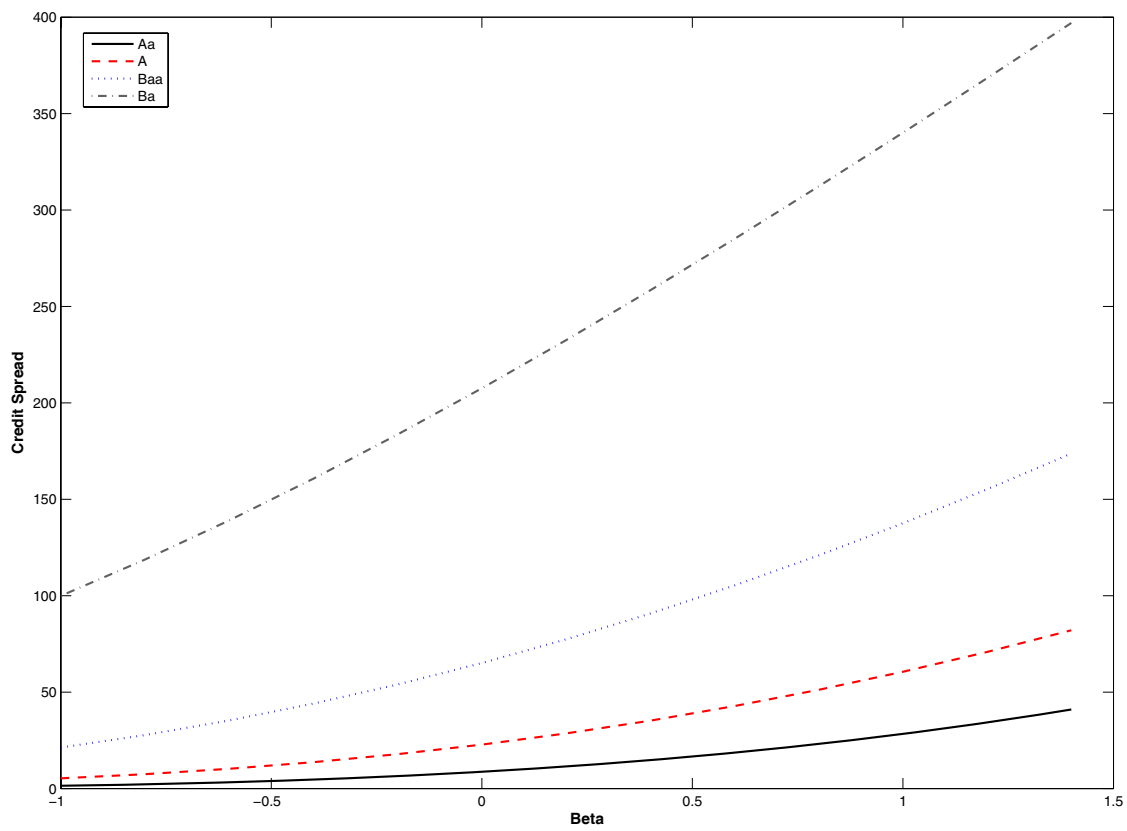


TABLE 8

The Impact of the Initial Leverage Ratio on Credit Spreads

\begin{tabular}{l}
$\begin{array}{l}\text { Table } 8 \text { shows credit spreads (in basis points) resulting from this paper's model when the initial leverage ratio equals } 80 \% \\
\text { (base case), 100\%, and 120\% of the target leverage ratio. The other parameters are base case ones (see Subsection A } \\
\text { of Section V). The target leverage ratios are defined in Table 2. } \\
\text { Initial Leverage of Target }\end{array}$ \\
\hline
\end{tabular}

\section{Special Case: Distressed versus "Fallen Angel" Firms}

In this subsection, we focus on two hypothetical firms. ${ }^{19}$ One is a distressed or "junk" firm whose asset volatility is high $(\sigma=0.4)$ while its current firm value is low. The second firm is a so-called fallen angel, whose asset volatility is moderate ( $\sigma=0.2$ ) while its firm value is low. More precisely, we assume that both firms' initial leverage ratio is equal to $110 \%$ of their target leverage ratios. Also, both firms are assumed to have the same beta equal to 0.75. In Figure 2, we plot both firms' term structure of credit spreads. We can see that the difference in the asset volatility of these two firms and, hence, the difference between their correlations with the stock market index, results in a dramatic difference in their credit spreads, especially for short maturity bonds. The distressed firm has much higher credit spreads and its term structure of credit spreads is more humped.

Following Acharya and Carpenter (2002), we next study the sensitivity (delta) of these two firms' bond prices to the firm value (Figure 3). It turns out that short maturity bonds (up to one year) of the distressed firm are the most sensitive to changes in the firm value. For the fallen angel firm, the sensitivity reaches its peak for about four-year bonds. Thereafter, the delta of both firms' bonds decreases as the time to maturity increases. These distinct sensitivities can have valuable implications for the hedging of corporate bond portfolios. In particular, it follows that it is more expensive to hedge very short-term bonds issued by distressed firms and long-term bonds issued by fallen angels.

\footnotetext{
${ }^{19} \mathrm{We}$ are grateful to the referee for suggesting the comparison between a fallen angel and a distressed firm.
} 
FIGURE 2

The Impact of the Assets Volatility on Credit Spreads

Figure 2 shows Ba bond credit spreads for the distressed firm ( $\sigma=0.4$ and the initial leverage equals $110 \%$ of the target) and the so-called fallen angel firm ( $\sigma=0.2$ and the initial leverage equals $110 \%$ of the target). The other parameters are base case ones (see Subsection A of Section V).

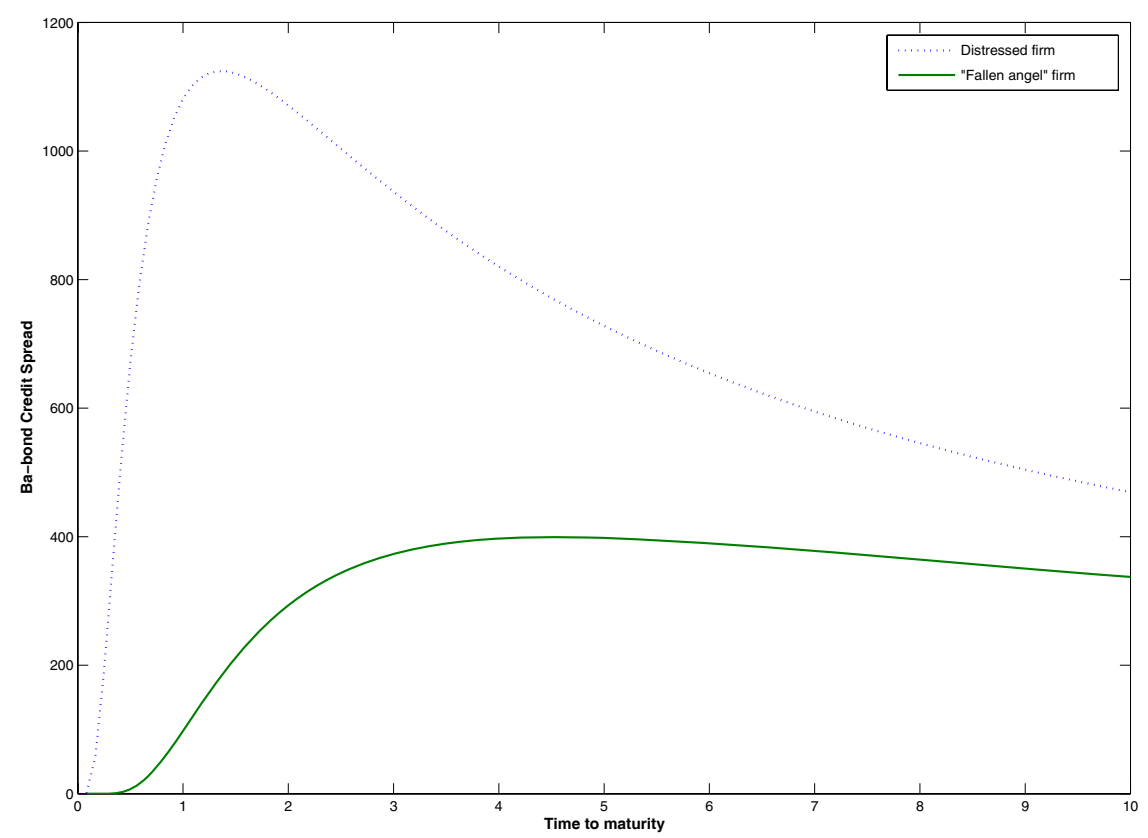

\section{Concluding Remarks}

We build a structural two-factor model of default where the stock market index is one of the stochastic factors. In our model, the performance of the stock market index serves as a proxy for the business climate. We allow the firm to adjust its capital structure and, hence, its leverage ratio, in response to changes in the firm value and to changes in the business climate. Our modeling of the dynamics of the firm's leverage ratio is based on the theoretical and empirical findings regarding the firm's capital structure choices. In particular, our model captures the fact that firms have mean-reverting leverage ratios and tend to issue equity rather than debt during economic expansions.

We compare the explanatory power of our model with the Longstaff and Schwartz (1995), Collin-Dufresne and Goldstein (2001), and Merton (1974) models. The comparison shows that our model yields higher credit spreads than these three models for all investment grade bonds irrespective of their maturities (except four-year Aaa and Aa bonds) and that it clearly dominates the structural models in the case of long-term spreads. These results suggest that the stock market dynamics matter more for corporate bond pricing than the dynamics of interest rates. Further empirical studies are needed to test the validity of this conjecture. 
FIGURE 3

The Bond Price Sensitivity (Delta) to the Firm Value

Figure 3 shows Ba bond price sensitivity to the firm value for the distressed firm ( $\sigma=0.4$ and the initial leverage equals $110 \%$ of the target) and the so-called fallen angel firm ( $\sigma=0.2$ and the initial leverage equals $110 \%$ of the target). The other parameters are base case ones (see Subsection A of Section V).

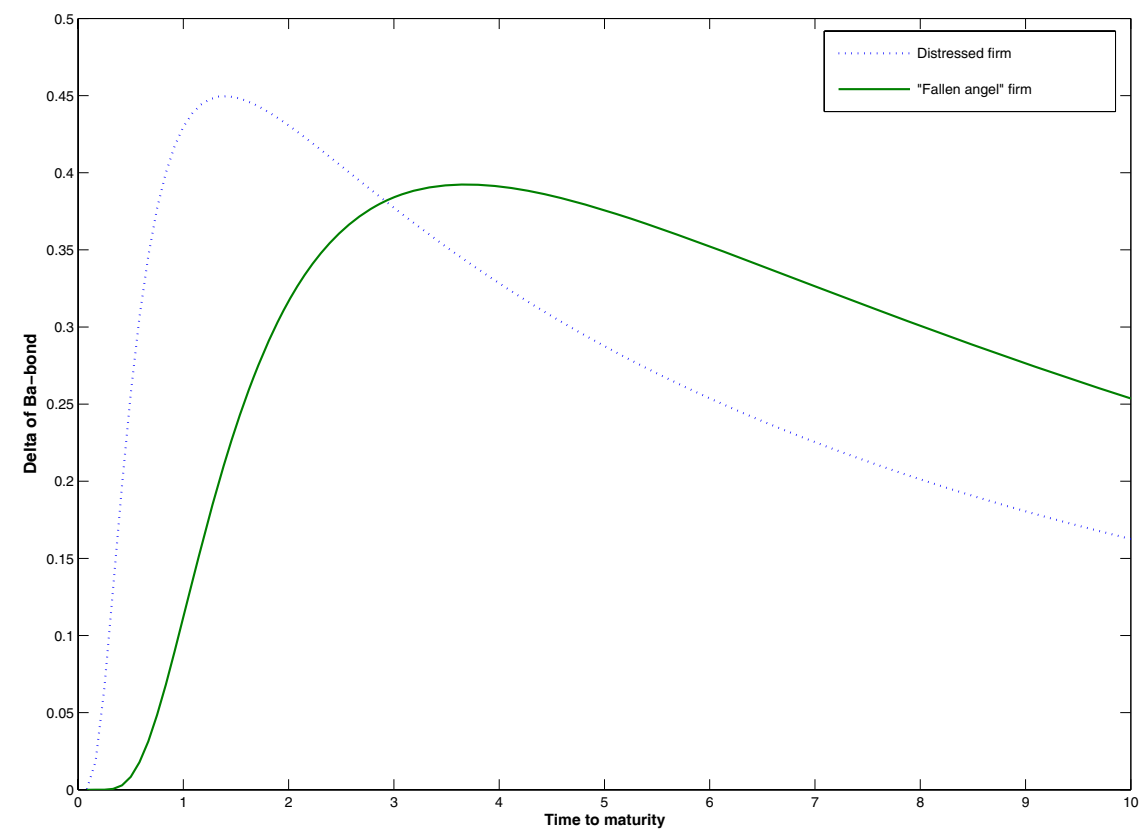

Our model also suggests that the assets beta and the correlation between the firm asset and the performance of the stock market index positively influence credit spreads. Therefore, our model has the potential to explain why credit spreads are different within the same credit rating groups. The model also shows that distressed firms and so-called fallen angels display distinct term structure of credit spreads, the latter being much more humped in the case of distressed firms. Finally, our model suggests a negative impact of the stock market performance on credit spreads that corroborates the stylized fact that credit spreads are lower during economic expansions and higher during recessions.

One of the limitations of our model is that it relies on the estimation of a large set of parameters. Thus, assuming that one is able to identify the appropriate benchmark index, one must further estimate the parameters governing the firm value and the benchmark index dynamics, the correlation coefficient between the firm asset and the stock index returns, and all the parameters entering the logleverage dynamics (6). Thus, to apply our corporate bond pricing model meaningfully, there is a need for more studies on the empirical properties of firms' leverage ratios dynamics. Finally, this study relies on a constant recovery rate, whereas empirical studies suggest that the recovery rate is time varying and that 
it also depends on the business climate (see, for example, Keenan (1999)). It is possible to extend or model to capture the dependency of the recovery rate on the business cycle. This extension is left for future research.

\section{Appendix A. Justification of the Log-Leverage Dynamics in Assumption 6}

In this Appendix, we show that an appropriate modeling of the firm's debt issuance policy, together with the given dynamics of the firm value process in equation (1), are sufficient to obtain the dynamics of the firm log-leverage ratio as specified in equation (6). For that purpose, we start by assuming that the book value of the firm's debt is equal to the weighted average of the past firm values and of the performance of the stock market index,

$$
D_{t}=e^{-\nu}\left[\sum_{s=-\infty}^{t}\left(V_{s}\left(\frac{I_{s}}{I_{s}}\right)^{-\delta}\right)^{e^{-\lambda(t-s)}}\right]^{\lambda},
$$

where $\delta$ is a positive constant reflecting a negative relation between the firm's debt issuance policy and the stock market performance, $\nu$ is the adjustment factor, and the parameter $\lambda$ is supposed to be a positive constant. Such a modeling of the firm's book value of debt implies that the latter is a function of both the historic firm values and the performance of the stock market index. Notice that the greater the value of the parameter $\lambda$, which is a sort of "memory" parameter, the more weight is put on the most recent history. Also, this modeling implies the following interpretation. First, there is a positive relation between the firm's face value of debt and the historic firm values. This implication is quite intuitive since richer and larger firms can afford to have more nominal debt. Second, there is a negative relation between the firm's book value of debt and the performance of the stock market index. This modeled implication is based on the empirical evidence of firm's debt issuance policies and the stock market performance (for details, see Section II). Namely, firms tend to increase their debt levels during recession periods, i.e., when the performance of the stock index is poor, and decrease debt levels during periods of economic expansion when the performance of the stock market index is strong.

Translating equation (A1) into continuous-time and switching to log-variables we obtain

$$
D_{t}=e^{-\nu+F_{t}},
$$

where

$$
F_{t}=\lambda \int_{-\infty}^{t}\left(e^{-\lambda(t-s)} y_{s}-\delta e^{-\lambda(t-s)} \psi_{s}\right) d s,
$$

and $y_{s}=\log V_{s}, \psi_{s}=\log \left(I_{s} / \bar{I}_{s}\right)$.

Thus,

$$
\begin{gathered}
\log \left(D_{t}\right)=-\nu+\lambda \int_{-\infty}^{t}\left(e^{-\lambda(t-s)} y_{s}-\delta e^{-\lambda(t-s)} \psi_{s}\right) d s . \\
d\left(\log D_{t}\right)=\lambda\left(y_{t}-\nu-\delta \psi_{t}-\log D_{t}\right) d t .
\end{gathered}
$$

The above equation represents the debt issuance policy that is positively related to the $\log$-firm value $y_{t}$, negatively related to the stock index performance $\psi_{t}$, and to the $\log$ level of the book value of debt itself. The first two implications agree with our earlier discussion, whereas a negative relation between changes in debt and the level of debt itself is in agreement with the trade-off theory of firms' capital structure. 

equity as

Similar to the modeling of the firm's book value of debt, we can model the firm's

$$
E_{t}=e^{-\nu_{e}}\left[\sum_{s=-\infty}^{t}\left(V_{s}\left(\frac{I_{s}}{I_{s}}\right)^{\delta_{e}}\right)^{e^{-\lambda_{e}(t-s)}}\right]^{\lambda_{e}},
$$

where $\delta_{e}$ is a positive constant reflecting the positive relation between the firm's level of equity capital and the stock market performance. Equation (A3) implies that the firm's equity issuance policy can be written as

$$
d\left(\log E_{t}\right)=\lambda_{e}\left(y_{t}-\nu_{e}+\delta_{e} \psi_{t}-\log E_{t}\right) d t .
$$

Analyzing the impact of the stock market performance on the firm's equity and debt issuance policies (A4) and (A2), we see that after periods of high stock index performance the firm tends to issue more equity and at the same time reduce its expensive debt at the expense of the newly issued equity and possibly of the available cash slack. On the other hand, after periods of poor stock index performance, the firm prefers to issue additional debt, as follows from equation (A2) and at the same time buy back a part of its equity at the expense of newly issued debt and possibly with available cash. Thus, we see that both equity and debt issuance policies are interrelated to some extent, and both are affected by the stock market performance.

Finally, to derive the dynamics of the log-leverage ratio, it is sufficient to consider the debt issuance policy as stated in equation (A2). Indeed, recall that $l_{t}=\log \left(D_{t} / V_{t}\right)=$ $\log D_{t}-y_{t}$. Thus, using equations (A2) and (2) we obtain

$$
\begin{aligned}
d l_{t} & =d\left(\log D_{t}\right)-d \log V_{t}=\lambda\left(y_{t}-\nu-\delta \psi_{t}-\log D_{t}\right) d t-d y_{t} \\
& =-\lambda\left(\nu+\delta \psi_{t}+l_{t}\right) d t-\left(r-\delta_{V}-\frac{\sigma^{2}}{2}\right) d t-\sigma d W_{t}^{Q} \\
& =\lambda\left(\bar{l}_{t}-\delta \psi_{t}-l_{t}\right) d t-\sigma d W_{t}^{Q}
\end{aligned}
$$

where $\bar{l}_{t}=(1 / \lambda)\left(\delta_{V}+\left(\sigma^{2} / 2\right)-r\right)-\nu$. This ends the justification of our assumption about the dynamics of the log-leverage ratio as stated in equation (6).

\section{Appendix B. Proof of Proposition 1}

For notational simplicity, we study the unconditional variance (i.e., $s=0$ ). For the conditional variance, all the derivations can be easily performed in the same way. Collecting terms that stand for the correlation coefficient $\rho$ in equation (C1) in Appendix C, we obtain

$$
\operatorname{Var}_{0}\left[l_{t}\right]=\{\ldots\}+K \sigma\left[\frac{1}{\lambda}\left(e^{-2 \lambda t}-1\right)+\frac{2}{\lambda+\theta}\left(1-e^{-(\lambda+\theta) t}\right)\right] \rho .
$$

If $\phi>0, \gamma>0, \sigma>0$, and $0<\lambda<\theta$, then $K=\phi \gamma \lambda /(\lambda-\theta)<0$, and it remains to show that the expression in brackets on the right-hand side of the above expression is negative. Consider the following function,

$$
f(\theta, \lambda)=\frac{1}{\lambda}\left(e^{-2 \lambda t}-1\right)+\frac{2}{\lambda+\theta}\left(1-e^{-(\lambda+\theta) t}\right) .
$$

For any fixed $\lambda$, the above function decreases with $\theta$. Indeed,

$$
\frac{d f(\theta, \lambda)}{d \theta}=-\frac{1}{(\lambda+\theta)^{2}}\left[1-\frac{1+(\lambda+\theta) t}{e^{(\lambda+\theta) t}}\right]<0
$$

because of the well-known result that $e^{x}>1+x \forall x>0$.

We show that function $f$ is strictly decreasing in $\theta$ for each fixed $\lambda$. Also, for every $\lambda, f(\theta=\lambda, \lambda) \equiv 0$. Given the above results, we conclude that $f(\theta>\lambda, \lambda)<0$ and by this we complete the proof. 


\section{Appendix C. Proof of Proposition 2}

See the proof of Proposition 2 in Collin-Dufresne and Goldstein (2001). We present the expressions for the first two moments of $l_{t}$ and $\psi_{t}$.

Solving equations (6) and (5) we obtain

$$
\begin{aligned}
l_{t} & =e^{-\lambda(t-s)}\left[l_{s}+\lambda \int_{s}^{t} e^{\lambda(u-s)} \bar{l}\left(\psi_{u}\right) d u-\sigma \int_{s}^{t} e^{\lambda(u-s)} d W_{u}^{Q}\right] \quad s<t \\
\psi_{t} & =e^{-\theta(t-s)}\left[\psi_{s}+\left(r-\delta_{i}-\frac{1}{2} \gamma^{2}\right) \int_{s}^{t} e^{\theta(u-s)} d u+\gamma \int_{s}^{t} e^{\theta(u-s)} d Z_{u}^{Q}\right] \quad s<t .
\end{aligned}
$$

Then,

$$
\begin{aligned}
\operatorname{Var}_{s}\left[l_{t}\right]= & {\left[\frac{K \sigma \rho}{\lambda}-\frac{K^{2}+\sigma^{2}}{2 \lambda}\right] e^{-2 \lambda(t-s)}+2\left[\frac{K^{2}-K \sigma \rho}{\lambda+\theta}\right] e^{-(\lambda+\theta)(t-s)} } \\
& -\frac{K^{2}}{2 \theta} e^{-2 \theta(t-s)}+K^{2}\left(\frac{1}{2 \theta}-\frac{2}{\lambda+\theta}+\frac{1}{2 \lambda}\right) \\
& +\frac{\sigma^{2}}{2 \lambda}+2 K \sigma \rho\left(\frac{1}{\lambda+\theta}-\frac{1}{2 \lambda}\right) \\
\operatorname{Var}_{s}\left[\psi_{t}\right]= & \frac{\gamma^{2}}{2 \theta}\left(1-e^{-2 \theta(t-s)}\right) \\
\operatorname{Cov}_{s}\left[l_{t}, \psi_{t}\right]= & \gamma\left[\frac{K}{2 \theta}\left(e^{-2 \theta(t-s)}-1\right)+\frac{K-\sigma \rho}{\lambda+\theta}\left(1-e^{-(\lambda+\theta)(t-s)}\right)\right]
\end{aligned}
$$

where $K=\phi \gamma \lambda /(\lambda-\theta)$.

\section{References}

Acharya, V. V., and J. N. Carpenter. "Corporate Bond Valuation and Hedging with Stochastic Interest Rates and Endogenous Bankruptcy." Review of Financial Studies, 15 (2002), 1355-1383.

Altman, E. I.; B. Brady; A. Resti; and A. Sironi. "The Link between Default and Recovery Rates: Implications for Credit Risk Models and Procyclicality." Working Paper, New York University (2002).

Anderson, R. W., and S. Sundaresan. "Design and Valuation of Debt Contracts." Review of Financial Studies, 9 (1996), 37-68.

Bancel, F., and U. R. Mittoo. "The Determinants of Capital Structure Choice: A Survey of European Firms." Working Paper, University of Manitoba (2002).

Barnhill, T. M., and W. F. Maxwell. "Modeling Correlated Market and Credit Risk in Fixed Income Portfolios." Journal of Banking and Finance, 26 (2002), 347-374.

Chen, N. "Financial Investment Opportunities and the Macroeconomy." Journal of Finance, 46 (1991), 529-554.

Choe, H.; and R. W. Masulis; and V. Nanda. "Common Stock Offerings across the Business Cycle." Journal of Empirical Finance, 1 (1993), 3-31.

Collin-Dufresne, P., and R. S. Goldstein. "Do Credit Spreads Reflect Stationary Leverage Ratios?" Journal of Finance, 56 (2001), 1929-1957. 
Collin-Dufresne, P.; R. S. Goldstein; and S. J. Martin. "The Determinants of Credit Spread Changes." Journal of Finance, 56 (2001), 2177-2208.

Duffie, D., and K. J. Singleton. "Modeling Term Structures of Defaultable Bonds." Review of Financial Studies, 12 (1999), 687-720.

Fama, E. F., and K. R. French. "Business Conditions and Expected Returns on Stocks and Bonds." Journal of Financial Economics, 25 (1989), 23-49.

Fama, E. F., and K. R. French. "Testing Tradeoff and Pecking Order Predictions about Dividends and Debt." Review of Financial Studies, 15 (2002), 1-33.

Franks, J. R., and W. N. Torous. "An Empirical Investigation of U.S. Firms in Reorganization.” Journal of Finance, 44 (1989), 747-769.

Friedman, B. M., and K. N. Kuttner. "Money, Income, Prices, and Interest Rates." American Economic Review, 82 (1992), 472-492.

Graham, J. R., and C. R. Harvey. "The Theory and Practice of Corporate Finance: Evidence from the Field." Journal of Financial Economics, 60 (2001), 187-24.

Guha, D., and L. Hiris. "The Aggregate Credit Spread and the Business Cycle." International Review of Financial Analysis, 11 (2002), 219-227.

Hovakimian, A.; T. Opler; and S. Titman. "The Debt-Equity Choice." Journal of Financial and Quantitative Analysis, 36 (2001), 1-24.

Huang, J., and M. Huang. "How Much of the Corporate-Treasury Yield Spreads is Due to Credit Risk?" Working Paper, New York University (2002).

Jarrow, R. A.; D. Lando; and S. M. Turnbull. "A Markov Model for the Term Structure of Credit Risk Spreads." Review of Financial Studies, 10 (1997), 481-523.

Keenan, S. C. "Historical Default Rates of Corporate Bond Issuers, 1920-1998." Moody's Global Credit Research, (1999).

Landschoot, A. V. "The Determinants of the Euro Term Structure of Credit Spreads." Working Paper, Ghent University (2003).

Leland, H. E. “Corporate Debt Value, Bond Covenants, and Optimal Capital Structure.” Journal of Finance, 49 (1994), 1213-1252.

Leland, H. E., and K. Toft. "Optimal Capital Structure, Endogenous Bankruptcy, and the Term Structure of Credit Spreads.” Journal of Finance, 51 (1996), 987-1019.

Longstaff, F. A., and E. Schwartz. "A Simple Approach to Valuing Risky Fixed and Floating Rate Debt.” Journal of Finance, 50 (1995), 789-821.

Lustig, H. "Market Price of Aggregate Risk and the Wealth Distribution.” Working Paper, University of Chicago (2002).

Marsh, P. "The Choice between Equity and Debt: An Empirical Study." Journal of Finance, 37 (1982), 121-144.

Merton, R. C. "On the Pricing of Corporate Debt: The Risk Structure of Interest Rates." Journal of Finance, 29 (1974), 449-470.

Moore, G. H. "Business Cycles, Inflation and Forecasting." National Bureau of Economic Research Studies in Business Cycles (1980).

Standard \& Poor's. "Corporate Ratings Criteria." (2002).

Taggart, R. “A Model of Corporate Financing Decisions.” Journal of Finance, 32 (1977), 1467-1484.

Weiss, L. A. "Bankruptcy Resolution: Direct Costs and Violation of Priority Claims." Journal of Financial Economics, 27 (1990), 285-314.

Zhou, C. "The Term Structure of Credit Spreads with Jump Risk." Journal of Banking and Finance, 25 (2001), 2015-2040. 